\title{
Comparison and Choice of Supply and Driver Unit for Power LED Luminary
}

\author{
Ilya Galkin ${ }^{1}$, Ansis Avotinsh $^{1}$, Alexander Suzdalenko ${ }^{1}$, Leonids Ribickis ${ }^{1}$ \\ ${ }^{1}$ Riga Technical University, Faculty of Power and Electrical Engineering, IEEI-IEEK (Riga, Latvia) \\ gia@eef.rtu.lv, ansis@eef.rtu.lv, suzdalenko@ellat.lv, leonids.ribickis@rtu.lv
}

\begin{abstract}
LED lighting technology in the context of development of Riga city illumination system. The main content of the presented report is the analysis of the photometrical and electrical performance of power LEDs at different supply and driving conditions. Possible configurations of the LED luminaries are described, as well as experimentally tested and compared. Conclusions regarding the further development of the LED luminaries are made.
\end{abstract}

\section{LUMINARIES OF RigA CITY ILLUMINATION SYSTEM}

Riga city lighting system has three main goals to achieve: to provide safety for all type traffic users on road, to provide visibility of pedestrians and their safety, and to improve environment at night.

Main maintenance costs for Riga city illumination system are related with electrical energy consumption. In 1995 Riga started to change high pressure mercury vapor lamps (400W and $250 \mathrm{~W})$ to high pressure sodium lamps $(250 \mathrm{~W}$ and $150 \mathrm{~W})$. It made possible to reduce energy consumption from $12,7 \mathrm{MW}$ to $6,7 \mathrm{MW}$ remaining the same illumination level and costs for electrical energy consumption, due to tenfold raise of electrical energy tariff from 1993. As Riga city is growing, the total energy consumption for illumination systems is also growing and a new solution is necessary.

To compare energy efficiency of different light sources, luminous efficacy in lumens per watt $(1 \mathrm{~m} / \mathrm{W})$ should be determined, that means the amount of light produced for each watt of electricity consumed by the light source. Currently, the most efficacious white LEDs can perform similarly to fluorescent lamps, because they have very high correlated color temperatures (CCTs), often above $5000 \mathrm{~K}$, producing "cool white" light and "warm white" (2600K to $3500 \mathrm{~K})$.

Fluorescent and high-intensity discharge (HID) light sources need ballast, which provides a starting voltage and limits electrical current within the lamp. LEDs are currentdriven devices, their brightness and color varies with their forward current, IF and the LEDs forward voltage drop, UF. To solve this problem LEDs require supplementary electronics, usually called drivers. The driver converts line power to the appropriate voltage and current, and may also include dimming and/or color correction controls. Most available LED drivers are typically efficient for about $85 \%$. So LED efficacy should be discounted by $15 \%$ to account for the driver. For a rough comparison, the range of luminous efficacies for traditional and LED sources, including ballast and driver losses as applicable, are demonstrated below.
TABLE I

LUMINOUS EFFICIENCY FOR DIFFERENT LIGHT SOURCES [1]

\begin{tabular}{|c|c|}
\hline Light Source & $\begin{array}{c}\text { Typical Luminous } \\
\text { Efficacy Range in lm/W }\end{array}$ \\
\hline Incandescent (no ballast) & $10-18$ \\
\hline Halogen (no ballast) & $15-20$ \\
\hline Compact fluorescent (CFL) (incl. ballast) & $35-60$ \\
\hline Linear fluorescent (incl. ballast) & $50-100$ \\
\hline Metal halide (incl. ballast) & $50-90$ \\
\hline Cool white LED 5000K (incl. driver) & $47-64$ \\
\hline Warm white LED 3300K (incl. driver) & $25-44$ \\
\hline
\end{tabular}

\section{BASIC FEATURES OF LED TECHNOLOGY}

The fast development of LED (Light Emitting Diode) technology, also called "a light for the 21 st century" has a great potential to achieve these efficiency improvements while maintaining high performance and reliability that supersede many currently used sources, like conventional incandescent bulb and fluorescent bulb. This technology is already introduced into a broad range of applications.

Physically, LEDs operate like p-n junction diodes, when a positive differential voltage is applied across the anode and cathode, an electron is recombined with a hole, and it releases energy. The released energy can be in the form of emissions in the optical range, using different $p-n$ junction materials. The wavelength of the emitted light depends on the band gap characteristics of its $p-n$ junction material. LED materials have relatively low reverse breakdown voltages since they have relatively low band gaps. Semiconductor materials used to produce LEDs include gallium phosphide, indium gallium nitride, silicon, silicon carbide, diamond, zinc selenide and some others.

TABLE II

LED WAVELENGTHS OF DIFFERENT DYE MATERIALS

\begin{tabular}{|l|l|l|l|}
\hline $\begin{array}{l}\text { Wavelength } \\
(\mathrm{nm})\end{array}$ & Color name & $\begin{array}{l}\text { Forward voltage } \\
\left(\mathrm{U}_{\mathrm{F}} @ 20 \mathrm{~mA}\right)\end{array}$ & $\begin{array}{l}\text { LED Dye } \\
\text { Material }\end{array}$ \\
\hline 940 & Infrared & 1,5 & $\mathrm{GaAlAs} / \mathrm{GaAs}$ \\
\hline 635 & High eff. Red & 2 & $\mathrm{GaAsP} / \mathrm{GaP}$ \\
\hline 570 & Super lime green & 2 & $\mathrm{InGaAlP}$ \\
\hline 430 & Ultra Blue & 3.8 & $\mathrm{SiC} / \mathrm{GaN}$ \\
\hline $8000 \mathrm{~K}$ & Cool white & 3.6 & $\mathrm{SiC} / \mathrm{GaN}$ \\
\hline
\end{tabular}


Basically LEDs are chosen according to their spectra and consumed energy. The important parameters of LEDs are: IF - maximal forward current; VF - maximal forward voltage; $\Theta$ - viewing angle. The constructed luminary's working parameters may be calculated from the diagrams, that demonstrate luminous flux dependency on forward current and junction temperature.

Too high temperature can permanently damage LED, or change its luminous flux. The luminous flux values given by LED manufacturers are based on LED junction temperature (Tj) of $25^{\circ} \mathrm{C}$, tested under conditions that are different from them in reality. LEDs in a well-designed luminary with adequate heat sinking will produce $10 \%-15 \%$ less light than indicated by the "typical luminous flux" rating.

The average life expectancy of a LED light is 60,000 hours, which greatly reduces the maintenance costs of lighting. Color has high purity and brightness. LED products almost cover the whole spectrum of visible light and have high brightness of the color. LED lights are environmentally friendly, because they have no mercury in light source and no ultraviolet radiation in beam of light, allowing them to meet special illumination quality requirements.

As a kind of solid light source LED is shock resistant. The surface of LED light source can be safely touched. LED light has strong emitting direction and makes good use of luminous flux. LED can be powered with direct current which is safer in use and started up at least in milliseconds with no influence of startup temperature and realizes the full luminous flux instantly.

\section{POWER SUPPLIES FOR LED LUMINARIES}

LEDs themselves are low voltage semiconductor elements (diodes) that are not directly compatible with common AC networks. Therefore some converter is always required to supply LED luminary.

If the luminary must provide some constant amount of light its power supply must ensure the corresponding constant current of the LEDs. This can be done with some traditional equipment like voltage source and series balancing resistor or current regulator (more efficient and preferable solution).

Light dimming is only possible with more complex power supply. Preliminary analysis revealed three basic light control approaches: 1) regulation of value of LED's current; 2) pulse width modulation of the current; 3) grouping and sectional powering of LEDs. Besides that it is possible to combine the first two approaches with the third one.

\section{A. Regulation of current}

The current regulator of the luminary may be based on a typical closed loop that includes a current feedback with current sensor, error amplifier, some PI or PID regulator and power converter. It is, however, more difficult to find an integrated solution for such current loop while discrete implementation is bulky because of the measurement of current. That is why it was decided to adopt an existing voltage regulator to the discussed application [3].

Such voltage regulators are also based on the closed loops, but they include voltage feedbacks. The sensor of the feedback is usually a voltage divider that in steady state keeps $1.235 \mathrm{~V}$ in its midpoint. The upper and lower parts of such divider may be quite arbitrary chosen, but their ratio defines the output voltage. The divider may be described as the branch with constant current that is set by means of the lower resistor at the level of $1.235 \mathrm{~V} / \mathrm{R}_{\mathrm{LOW}}$. Then the upper resistor may be even non-linear, for example, series of LEDs - its current will also be stabilized [4].

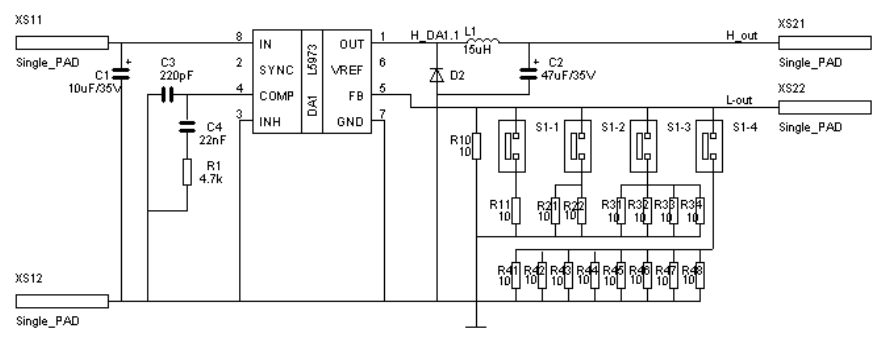

a) electrical diagram

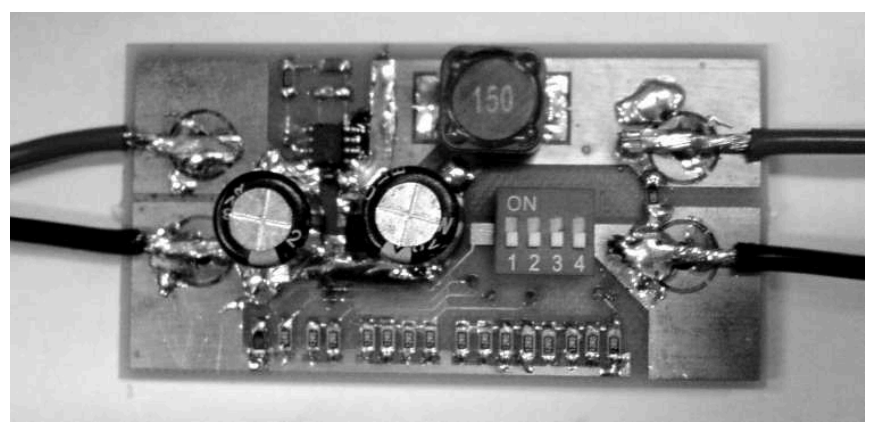

b) laboratory sample

Fig. 1. The current regulator of LED luminary that is based on an existing integrated voltage regulator.

The proposed example (Fig. 1) is based on the integrated circuit L5973. In order to adjust the current from $0.35 \mathrm{~A}$ to $2.8 \mathrm{~A}$ (for tested $70 \mathrm{~W}$ luminary), lower resistor is changed from 3.5 to $0.44 \mathrm{Ohm}(1.235 / 0.35$ and $1.235 / 2.8-$ respectively). Power losses in the lower resistor are changed from 0.43 to $3.46 \mathrm{~W}$ (less than $5 \%$ ) that is acceptable for laboratory purposes.

\section{B. Pulse with modulation of current}

This approach is based on the phenomenon of inertia of the human eye. If a luminary is blinking fast enough then such blinking is recognized as dimming. The depth of the dimming depends on the duty cycle of the signal (Fig. 2-a). There are several possible realizations of this approach.

1) Direct PWM signal may be applied to the transistor commutating DC voltage to series connected LEDs and balancing resistor.

2) Inverted PWM signal may be applied to the transistor short-circuiting the series connected LEDs. 
3) Direct PWM signal may be used as enable signal for the current stabilizing IC [4][5].

For laboratory testing (Fig. 2-b) the first approach was used. PWM signal was taken from a laboratory signal generator and through a driver circuit applied to the transistor.

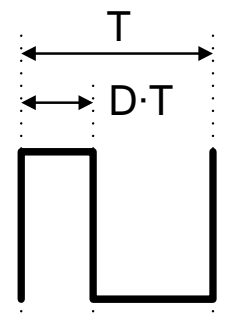

a) PWM signal

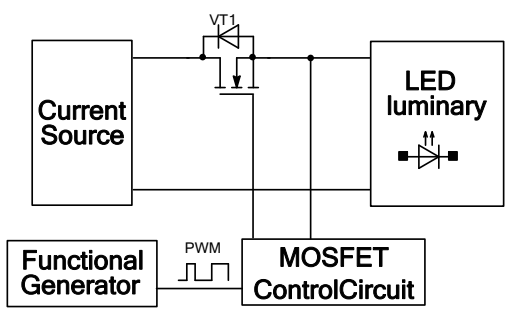

b) laboratory hardware
Fig.2. The current regulator of LED luminary that is based on an existing integrated voltage regulator.

\section{Commutation of groups}

If the luminary contains few lighting devices (for example, several LEDs) they can be switched on and off separately or in groups thus providing several steps of lighting. Utilization of the binary weighted groups gives more levels of lighting with more constant step between the levels. Of course, each group of LEDs requires its own power supply that, however, may be less complex (3 laboratory power supplies were used in the experiments) [6].

Since in the given research 7 LEDs are used it is efficient to use groups of 1, 2 and 4 diodes (Fig. 3-a and Fig. 3-b). Then there are 7 available levels of power and 7 levels of brightness (Fig. 3-c).

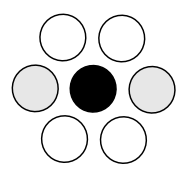

a) configuration

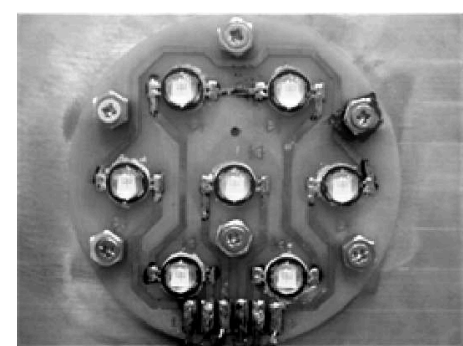

b) laboratory example

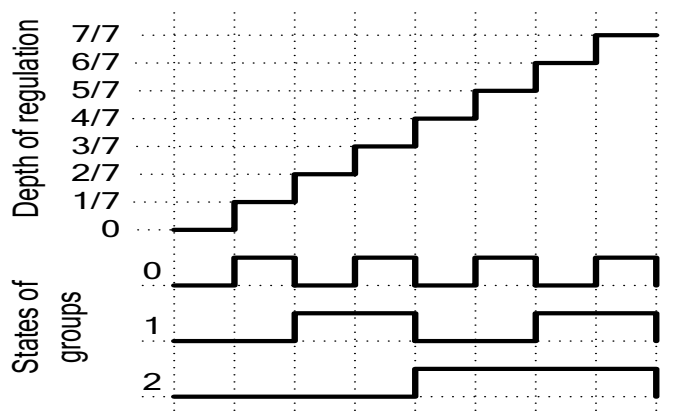

c) operation
Fig. 3. Grouping of lighting elements in the 70W 7 LED luminary.

\section{EXPERIMENTAL RESULTS}

The mentioned approaches were tested with 70W LED luminary that consists of 7 W724C0 LEDs $(2.8 \mathrm{~A}, 10 \mathrm{~W} \sim 80 \%$ of which is released as heat), the corresponding heatsink and connectors available for each binary weighted group of LEDs. The experiments were realized in order to find the most energy saving and cost effective solution, as well as to uncover the properties of dimming methods and their efficiency.

The current regulation, current PWM and group switching methods were tested with $1 / 7,3 / 7$ and $5 / 7$ of the parameter. Then the current regulation method requires $2.8 / 7=0.4 \mathrm{~A}, 1.2 \mathrm{~A}$ and $2.0 \mathrm{~A}$ levels of the current, PWM $-100 / 7 \approx 14.3 \%, 42.5 \%$ and $72.5 \%$, values of the duty cycle, but for the group switching $-1,3$, and 5 elements powered with rated current of $2.8 \mathrm{~A}$.

Typical light distribution over the explored surface is presented in Fig. 4. As it was expected the measured brightness is maximal just under the luminary and drop significantly (about $20 \%$ per $1 \mathrm{~m}$ ) across the distance. No other significant light spots or shadows are found. In whole this is typical lighting picture for luminary without reflectors, diffusers or other light equalization means.

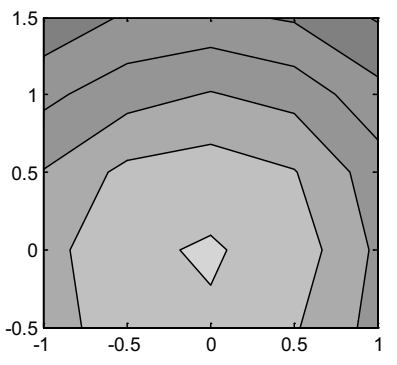

a) group switching

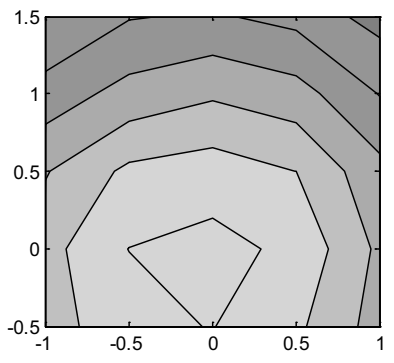

b) current PWM

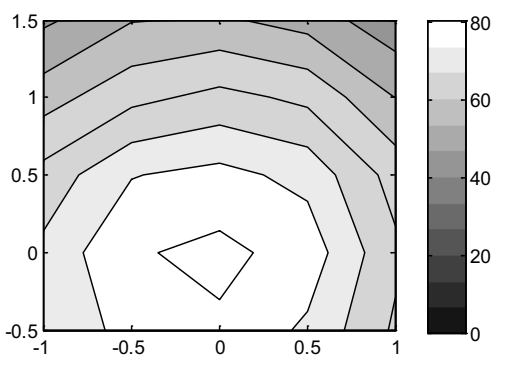

c) current regulation

Fig. 4. Lighting at 3/7 of control parameter taken with different types of the dimming

The similar picture could be presented for the other values of the regulation parameter. However, it is more important to compare brightness at different control approaches and at different levels of the corresponding control parameter that is provided in Table IV. It is obvious from this table that 
switching of groups and PWM provides quite linear regulation ( $9 \%$ and $8 \%$ respectively) while current regulation is highly non-linear $(24 \%)$. This phenomenon could be explained by non-linear lighting characteristic of LED itself. At the same time the current regulation approach gives more light at the same level of the control parameter.

TABLE IV

AVERAge Brightness [LX] AT DifFERENT POWER SuPPliES

\begin{tabular}{|l|c|c|c|}
\hline Type & $1 / 7$ & $3 / 7$ & $5 / 7$ \\
\hline Group switching & 16.4 & 49.8 & 74.9 \\
\hline Current PWM & 17.0 & 54.4 & 91.7 \\
\hline Current Regulation & 25.2 & 66.4 & 95.2 \\
\hline
\end{tabular}

Another table (Table V) represents the operation temperature of LED package. It shows that in PWM and current control modes the temperature depends on the operation parameter, but in group switching mode the operation LED temperature is about $100^{\circ} \mathrm{C}$.

TABLE V

LED OPERATION TEMPERATURES $\left[{ }^{\circ} \mathrm{C}\right]$ AT DifFERENT POWER SUPPLIES

\begin{tabular}{|l|c|c|c|}
\hline Type & $1 / 7$ & $3 / 7$ & $5 / 7$ \\
\hline Group switching & 96 & 96 & 103 \\
\hline Current PWM & 36 & 51 & 79 \\
\hline Current Regulation & 42 & 63 & 79 \\
\hline
\end{tabular}

The next significant comparison is comparison of the consumed power (Table VI). This table represents that current the regulation consumes less power for the same level of control parameter while the implemented and tested PWM is the most power consuming. However, these data depend a lot on the power calculation methodology. Also, it must be noted that alternative PWM approaches (for example, methods 2 and 3 from section III.B) might be more effective.

\section{TABLE VI}

CONSUMEd Power [W] AT DifFERENT POWER SuPPLIES

\begin{tabular}{|l|c|c|c|}
\hline Type Value & $1 / 7$ & $3 / 7$ & $5 / 7$ \\
\hline Group switching & 11.2 & 32.0 & 51.4 \\
\hline Current PWM & $10.8(10.5)$ & $38.3(34.9)$ & $71.8(59.9)$ \\
\hline Current Regulation & 8.5 & 28.0 & 49.2 \\
\hline
\end{tabular}

\section{CONCLUSIONS}

The first LED's for illumination were available 2-3 years ago, and various products now are available at the market. A year ago high power LED's were developed and soon we can expect next generation of LED products. Also prices for LED luminary for street illumination have been decreased for 20$45 \%$ for past years, becoming more attractive for city illumination system managing companies.
So far the described experiments demonstrate the effectiveness of the current control method. This conclusion has two sides. The first one, the lower is current the higher is efficacy of diodes $[1 \mathrm{~m} / \mathrm{W}]$. The second - lower current results in the reduced operating temperature of LEDs and, hence, in higher light output (smaller losses). The efficiency of all control methods is summarized in Fig.5.

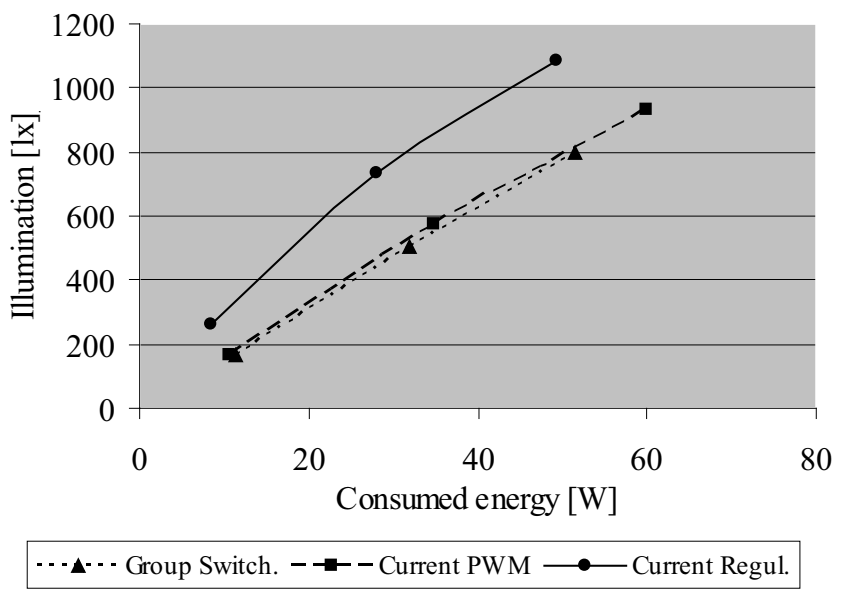

Fig. 5. Efficiency of dimming control methods

All LEDs have the same drawback - their lifetime directly depends on the operating temperature. Therefore the current control and PWM approaches are more preferable also from this point of view.

\section{REFERENCES}

[1] Measurement results of U.S. Department of Energy. Date October 2007. Brochure: Building Technologies Program.

[2] Давиденко Ю. Н. 500 схем для радиолюбителей. Современная схемотехника в освещении. Эффективное электропитание люминисцентных, галогенных ламп, светодиодов, элементов «Умного дома». - Санкт-Петербург: Наука и Техника, 2008. 320.1pp.;

[3] Freescale Semiconductor: High-Brightness LED Control Interface/ Application Note - Document Number: AN3321, Rev. 0, 10/2007 http://www.freescale.com/files/microcontrollers/doc/app_note/AN3321. pdf; Verified at 2009.07.10.

[4] National Semiconductor: LED Drivers for High-Brightness Lighting / Solution Guide - 2009.g. Vol. 1 - http://www.national.com/vcm/NSC Content/Documents/en_US/national_HB_LED_Lighting.pdf; Verified at 2009.07.10.

[5] National Semiconductor: Matching Driver to LED - 01/2008. - http:// www.national.com/appinfo/power/files/National_LED_White_Paper.pd f; Verified at 2009.07.10.

[6] National Semiconductor: LED Lighting Management Solutions/ Slection Guide - 2008. - http://www.national.com/appinfo/power/files/ lighting_solutions.pdf; Verified at 2009.07.10. 